clínico) para mais de 50\% (estudos de autópsia e ultra-som). Parâmetros clínicos como: sexo masculino, criança ou idoso, exposição à radiação ionizante, crescimento rápido, sinais/sintomas de invasão local e história familiar de carcinoma de tiróide ou polipose familiar aumentam o risco de malignidade. Desenvolvimento: Avaliação da função tiróidea, ultrasonografia e cintilografia não conseguem identificar com precisão os nódulos malignos. Entretanto, diagnosticado o nódulo, a medida do TSH deve ser feita para afastar hiper/hipotiroidismo como causa da doença. De acordo com especialistas, punção aspirativa por agulha fina (PAAF) é o método disponível mais eficaz para distinguir nódulos benignos e malignos, com elevada acurácia $(95 \%)$ e poucos resultados falso-negativos (1-8\%) e falso-positivos (1-11\%). Recentemente, um grande número de nódulos tem sido diagnosticado acidentalmente, em especial por ultra-som. Não há um consenso sobre o que fazer frente a esta nova situação, visto que puncionar todos os nódulos seria economicamente inviável. A presença de características ultra-sonográficas como: hipoecogenicidade, margens irregulares, fluxo vascular central e microcalcificações são sugeridas para melhor selecionar os nódulos candidatos à PAAF. Comentários: Recentemente, há grande preocupação a respeito do diagnóstico e conduta dos nódulos tiróideos não palpáveis. Características ultra-sonográficas motram-se úteis como preditores de malignidade, auxiliando na seleção dos nódulos suspeitos para a PAAF

Descritores: Nódulo da glândula tireóide. Neoplasias da glândula tiróide. Biópsia por agulha. Nódulos da glândula tiróide e ultra-sonografia. Cintilografia.

\section{PAPEL DOS METAIS NO DESENCADEAMENTO DE DOENÇAS AUTO-IMUNES: APRESENTAÇÃO DA IMUNOTOXICOLOGIA COMO NOVA CIÊNCIA}

\section{Cammarosano RAFA, Chicoli FA, Diaz TF, Doria PLS, Rocha KC}

katyacrrocha@hotmail.com

Introdução: Autoimunidade é um evento normal, enquanto doença autoimune resulta de uma alteração deste fenômeno. A etiologia desse desvio é considerada multi-fatorial, levando ao final à perda da auto-tolerância normal do Sistema Imune à componentes do próprio organismo. Fatores genéticos, hormonais e imunológicos sofrem alterações induzidas principalmente por fatores ambientais, como o aumento ao longo dos anos da quantidade de poluentes do ar, água e solo; os metais são os que mais contribuem para o desenvolvimento das doenças auto-imunes. Desenvolvimento: Iniciamos com uma revisão dos mecanismos imunológicos, abordando temas como a maturação e seleção de linfócitos B e T, tolerância central e periférica, seguido de uma descrição dos principais processos responsáveis pela quebra da tolerância imunológica. A seguir apresentamos a imunotoxicologia como a ciência que estuda o efeito de substâncias tóxicas no Sistema Imunológico, correlacionando esta com o papel dos metais no desenvolvimento de doenças auto-imunes. Comentários: Muitos poluentes ambientais são tóxicos para animais e humanos provocando variadas doenças ou a morte. Os poluentes podem ter um efeito direto ou indireto nas células imuno-competentes e nos mecanismos inespecíficos de defesa.Devido aos crescentes efeitos tóxicos causados por estes e respeitando quesitos científicos cada vez mais específicos e exigentes, surge a necessidade de desenvolver métodos para a avaliação desse agentes nocivos sobre o Sistema Imunitário.

Descritores: Sistema Imune. Doença autoimune. Imunotoxicologia. Fatores ambientais. Linfócitos. Metais.

\section{SÍNDROME RESPIRATÓRIA AGUDA GRAVE - CARACTERÍSTICAS CLÍNICAS E EPIDEMIOLOGICAS}

Appolonio PR, Carneiro A, Carneiro Neto M, Carvalho FRT, Gonçalez $\mathrm{DH}$,

eirabr@yahoo.com.br

Introdução: A Síndrome Respiratória Aguda Grave é a mais nova doença que vem mobilizando o mundo devido ao seu caráter epidêmico e sua alta taxa de mortalidade, e será descrita nesta monografia sob seus principais aspectos. Desenvolvimento: A Síndrome Respiratória Aguda Grave (SRAG) é um transtorno surgido na China entre o fim de 2002 e início de 2003 caracterizada por febre alta, tosse seca, falta de ar (dispnéia) e pneumonia atípica. O agente etiológico desta doença é um vírus coronaviridae. O contágio da doença, segundo a OMS, ocorre por transmissão direta, através de contato e secreções e o tratamento é feito com fármacos antiviróticos (ribavirina). A doença atingiu diversas partes do mundo, demonstrando caráter pandêmico, mas principalmente a China. Comentários: Diversas medidas foram tomadas por vários países em conjunto para combater a doença e evitar que ela não se alastrasse. Atualmente, a epidemia já é considerada sob controle.

Descritores: Etiologia. História. Mortalidade. Patologia. Terapia. Diagnóstico. Epidemiologia. Prevenção e Controle. Transmissão.

\section{TELOMERASE - UM MARCADOR BIOLÓGICO UBIQÜITÁRIO EM TUMORES}

El-Afiouni V, Hatakeyama TT, Nazato DM, Souto RP

debnazato@ig.com.br

Introdução: Oitenta e cinco por cento dos tumores apresentam atividade elevada da enzima telomerase, tornado esta molécula um dos marcadores moleculares mais largamente distribuído em neoplasias. Esta enzima é uma DNA polimerase capaz de estender os telômeros, que são as regiões terminais dos cromossomos lineares eucarióticos. A ação da telomerase evita a senescência celular que ocorre pelo encurtamento dos cromossomos após a replicação do DNA. Deste modo, a telomerase normalmente é encontrada em tecidos que apresentam alta taxa de divisão celular como epitélios e órgãos reprodutivos, mas não na maioria das células somáticas. Desenvolvimento: Nos processos tumorais, acredita-se que a ativação da telomerase seja necessária para a imortalização celular. De forma geral observa-se que atividade telomerásica é crescente conforme a malignidade dos tumores. A telomerase é um complexo ribonucleoproteico, constituído em humanos de um RNA (hTR) e de uma proteína catalítica (hTERT). Sua presença em amostras biológicas pode ser avaliada tanto através de um ensaio de atividade consistindo na amplificação da repetição do telômero (TRAP), quanto pela deteção de suas subunidades hTR e hTERT. Os principais obstáculos para a exploração da telomerase como alvo para o diagnóstico de neoplasias neste momento são técnicos, como a necessidade de padronização dos métodos de coleta e análise de resultados. Comentários: Tais dificuldades, não ofuscam o potencial da telomerase como um dos principais marcadores biológicos para o diagnóstico de câncer e servem de estímulo para o aprofundamento do conhecimento sobre esta molécula.

Descritores: Telômero. Telomerase. Câncer. Marcador biológico.

\title{
RELATOS DE CASO
}

051. DISTIREOIDISMO ASSOCIADO AO USO DA AMIODARONA: FISIOPATOLOGIA E TRATAMENTO

Hirai LK, Marumo S, Matuo FS, Oliveira FP, Santomauro AT, Úson RAS simarumo@yahoo.com.br

Introdução: A amiodarona é um potente antiarrítmico utlizado no tratamento de arritmias, e sua mais notável característica é a alta porcenta- gem de iodo que contém, aproximadamente $37 \%$ de seu peso molecular. Por isso como um de seus efeitos colaterais, a droga pode causar "distireoidismo" com hipotireoidismo (AIH) ou tireotoxicose (AIT) induzido por amiodarona, como ocorreu nos dois casos descritos. Devido ao grande valor da amiodarona no tratamento das arritmias é importante saber reconhecer e como atuar frente a essa disfunção tireóidea, porque em muitos casos o uso da droga é imprescindível à vida do paciente. Relato de Caso: Caso I: B. A. C., 48 anos, masculino, branco. Paciente 
portador de prolapso de válvula mitral, com diagnóstico de taquiarritmia em 1995 quando iniciou uso de amiodarona (200 mg/dia). Em 2000, apresentou quadro de fibrilação atrial, na investigação foi constatado TSH $<0,01 \mathrm{mU} / \mathrm{ml}(0,5-4,0), \mathrm{T}_{4} 1=1,72 \mathrm{ng} / \mathrm{dl}(0,8-1,7)$ e $\mathrm{T}_{3}=1,2 \mathrm{ng} / \mathrm{dl}(80-$ 180). Exceto pelo quadro de fibrilação atrial apresentou-se clinicamente eutiroideo. Nega qualquer antecedente tireopatia pessoal ou familiar. Caso II: M. C. A. 64 anos, feminina, branca. Em uso de amiodarona $(200 \mathrm{mg} /$ dia) há 10 anos por arritmia (sic). Refere ultrasom de tireóide com bócio multinodular, na investigação laboratorial: TSH $=20 \mathrm{um} / \mathrm{ml}, \mathrm{T} 41=0,7 \mathrm{ng} /$ dl e T3 $=84 \mathrm{ng} / \mathrm{dl}$. Ultrasom de tireóide com textura heterogênea, múltiplos nódulos menores que $5 \mathrm{~mm}$. Clinicamente eutiroidea. Comentários: O "distireoidismo" induzido pela amiodarona não ocorre em todos os pacientes que fazem uso da droga, e pode-se manifestar mesmo depois da retirada da droga. O tratamento na maioria dos casos é efetivo, no AIT tipo I está indicado o uso de tionamidas e percloratos, enquanto que no AIT tipo II corticoesteróides, nos casos resistentes existe a possibilidade da tireoidectomia. No AIH o restabelecimento do eutireoidismo é possível através da reposição com levotiroxina ou com a suspensão da droga.

Descritores: Amiodarona. Tireóide. Tireotoxicose. Hipotireoidismo.

\section{DUPLICAÇÃO GÁSTRICA INTRA TORÁCICA: RELATO DE CASO}

Akita Júnior J, Appolonio F, Cagno Filho R, Dall'Olio G, Fernandez PM, Oguro FM, Pollachi F, Wroclawski ML

betocagno@uol.com.br

Introdução: Os autores relatam um caso de recém nascido com diagnóstico pré-natal de formação cística intratorácica, associada à hidrocefalia e meningomielocele. O resultado anátomo patológico da peça cirúrgica confirmou o diagnóstico de duplicação gástrica intra-torácica. Relato de Caso: Recém-nascido com diagnóstico intra-útero de mielomeningocele, hidrocefalia e tumoração cística torácica à direita. À radiografia de tórax observou-se, desde o nascimento, imagem cística em ápice de hemitórax direito, confirmada por tomografia de tórax. Realizada toracotomia, onde se encontrou lesão cística sem comunicação com estruturas adjacentes; sendo realizada a retirada da mesma. O anátomo-patológico da peça cirúrgica revelou presença de formação cística revestida por epitélio gástrico antral, confirmando o diagnóstico de duplicação gástrica. Comentários: Duplicações císticas do intestino anterior são raras anomalias de desenvolvimento. Seu diagnóstico pode ser feito no pré-natal, ou em crianças com sintomas respiratórios ou digestivos que não respondem ao tratamento convencional. A retirada cirúrgica deve ser completa e o mais precoce possível para evitar complicações, recorrências, e mais tardiamente, malignização, sendo assim a melhor conduta terapêutica, com excelentes resultados pós-operatórios.

Descritores: Duplicação intestinal. Duplicação gástrica. Cisto broncogênico. Cisto mediastinal. Ultrassonografia pré-natal.

\section{ESCLEROSE TUBEROSA - DIAGNÓSTICO BASEADO EM EVIDÊNCIAS}

Bertolami A, Chaves FP, Hanania M, Moraes CFV, Mozetic V, Possendoro KA

flachaves@hotmail.com

Introdução: A Esclerose Tuberosa (ET) ou Doença de Bourneville é uma doença hereditária, neurocutânea e multisistêmica que se caracteriza pela presença de hamartomas em múltiplos órgãos como sistema nervoso central, rins, pele, coração, pulmão, olhos e ossos. A ET tem herança autossômica dominante, associada a uma mutação nos cromossomos 9q34 (ET tipo 1) e 16p13 (ET tipo 2), sendo o tipo 2 mais comum. Suas manifestações clínicas em sua forma clássica se caracterizam por epilepsia, retardo mental e angiofibromas faciais, caracterizando a tríade de Vogt. Segundo alguns autores, a ET tem incidência de 1:10.000 e não há preponderância racial ou de sexo. Relato de Caso: Relata-se um caso de paciente de 33 anos com esclerose tuberosa diagnosticada com a utilização de dados clínicos e exames de imagem, segundo os preceitos atuais. Deu-se ênfase para o diagnóstico não invasivo, uma vez que a paciente não apresentava condições clínicas para ser submetida a procedimentos diagnósticos invasivos. Comentários: Por meio da interação do quadro clínico apresentado pela paciente, citações da literatura, critérios diagnósticos e propedêutica armada encontrados na atualidade, foi possível que o diagnóstico fosse firmado, apesar da ausência de estudos anátomopatológicos mais invasivos.

Descritores: Esclerose tuberosa. Hamartoma

\section{ESCROTO AGUDO CAUSADO POR APENDICITE PERFURADA EM UMA HÉRNIA INGUINAL ENCARCERADA EM RECÉM NASCIDO PRÉ-TERMO: RELATO DE CASO}

Appolonio F, Cagno Filho R, Fernandez PM, Ferreira HG, Pollachi F, Vidoris AAC, Zanini RVR

fappolonio@yahoo.com

Introdução: $O$ encarceramento da hérnia inguinal é comum na infância, principalmente em recém-nascidos prematuros. A apendicite neonatal, por sua vez, é uma afecção rara nesta faixa etária. Geralmente está relacionada com megacolo congênito, enterocolite necrosante e hérnia inguinal encarcerada. De difícil diagnóstico, esta afecção relaciona-se com alta mortalidade neste grupo de pacientes. Relatos de apendicite neonatal em hérnia encarcerada são excepcionalmente raros. Os autores relatam um caso de escroto agudo devido a apendicite perfurada contida em uma hérnia inguinal encarcerada em um recém-nascido pré-termo. Relato de Caso: Recém-nascido pré-termo, apresentando quadro de escroto agudo, foi submetido a intervenção cirúrgica durante a qual foi diagnosticada apendicite aguda perfurada dentro do saco herniário. Realizada apendicectomia e correção da hérnia inguinal. O paciente teve boa evolução. Comentários: Apesar de rara, a apendicite aguda em hérnia inguinal encarcerada deve ser considerada no diagnóstico diferencial de um quadro de escroto agudo em recém-nascido prematuro.

Descritores: Apendicite. Escroto agudo. Hérnia inguinal. Hérnia de Amyand. Recém nascido

\section{EVOLUÇÃO DA HANSENÍASE NO PACIENTE HIV POSITIVO: RELATO DE DOIS CASOS}

Alessi R, Canavezzi AZ, Cvintal V, Ito LM, Kelendjian JF, Novais MAB Xavier WC

\section{alessi@uol.com.br}

Introdução: A hanseníase e o HIV são doenças endêmicas e de alta incidência no Brasil. Enquanto as relações do HIV com Mycobacterium tuberculosis e $M$. avium já estão bem documentadas, com o $M$. leprae não há associação certa, sendo os estudos epidemiológicos conflitantes e os relatos desta co-infecção, raros. Relato de Caso: Dois pacientes do ambulatório de hanseníase de Centro de Saúde Escola do Parque Capuava, ligado à Disciplina de Dermatologia da Faculdade de Medicina da Fundação do ABC, com HIV comprovada pelos métodos de ELISA e Western-Blot, e portadores do mal de Hansen, foram acompanhados por dois anos. Os pacientes já eram portadores de HIV e apresentaram hanseníase posteriormente ao início do tratamento antiretroviral, um desenvolvendo a forma tuberculóide e o outro, forma dimorfa virchowiana. Ambos apresentaram reação hansênica reversa (tipo I) mediada por imunidade celular e não houve alterações na resposta ao tratamento da hanseníase e suas manifestações, em relação da resposta esperada em pacientes não infectados pelo HIV. Comentários: Os relatos de caso apresentaram uma tendência de concordância aos trabalhos que sugerem ligação entre a imunodeficiência causada pela SIDA e o decurso das manifestações clínicas da hanseníase. É fato que o HIV alterou a epidemiologia das doenças micobacterianas, porém, o $M$. leprae se comporta de maneira distinta, necessitando assim de maiores estudos para elucidar tal relação.

Descritores: AIDS. HIV. SIDA. Hanseníase. Lepra. 


\section{FRATURAS DO ACETABULO COM CONGRUÊNCIA SECUNDÁRIA}

Aita MA, Campoe GM, Fujiki EN, Fukushima WY, Gasparotti E, Mascarenhas BVA, Oliveira KM, Tardini R

rtardini@uol.com.br

Introdução: Atualmente tem-se observado um aumento dos acidentes automobilísticos graves com traumas de alta energia que levam a um grande número de lesões associadas, dentre elas a fratura do acetábulo. O paciente politraumatizado com fratura do acetábulo gera uma grande dúvida na indicação de tratamento dessa fratura, nos casos em que a congruência articular é mantida pode-se optar pelo tratamento cirúrgico ou conservador. O tratamento conservador mantém o paciente restrito ao leito por grandes períodos levando a complicações pulmonares e produção de escaras se não for efetuada a profilaxia. Optou-se por este tratamento por se tratar de paciente jovem com boas condições clínicas, e cooperadora em relação aos cuidados e exercícios profiláticos. Relato de Caso: MRF, 28 anos, feminino, branca, do lar, natural de Fortaleza e procedente de Santo André há sete anos, viúva, analfabeta, católica, vítima de acidente automobilístico, atendida pela Unidade de Resgate no dia 07 de junho de 2003, deu entrada no Centro Hospitalar Municipal de Santo André, sendo realizado atendimento primário ao politraumatizado e diagnosticado fratura do acetábulo direito, fratura do úmero direito, ferimento corto contuso em região frontal direita e trauma abdominal fechado. Em relação à fratura do acetábulo, foi optado no tratamento inicial pela tração cutânea do membro inferior direito com três quilos no dia da internação aumentando progressivamente até 12 quilos, evoluindo com melhora do desvio e do quadro álgico, mantendo-se a congruência da articulação; durante o tratamento foram realizadas radiografias de controle. Optou-se por este tratamento por se tratar de paciente jovem com boas condições clínicas, e cooperadora em relação aos cuidados e exercícios profiláticos. Comentários: A abordagem conservadora permite uma possibilidade de estabilização clínica com agressão mínima ao doente, já acometido pelas lesões traumáticas associadas. Conclui-se que apesar de haver consenso em relação ao tratamento da fratura do acetábulo com desvio, cuja indicação é tratamento cirúrgico, existem indicações de exceção que apesar do conjunto estar desviado, ocorre uma congruência secundária que ainda permite a congruência articular. Apesar das inúmeras inovações de técnicas operatórias, o tratamento conservador pode ser realizado de maneira segura e eficaz com bons resultados ortopédicos em situações especiais. Atualmente, a paciente encontra-se no vigésimo quinto dia de internação com boa evolução clínica, melhora da dor e melhora significativa do desvio da fraturas das duas colunas do acetábulo direito, sob controle radiográfico e clínico.

Descritores: Trauma. Fratura. Acetábulo. Tratamento. Congruência.

\section{HANSENÍASE NA INFÂNCIA E ADOLESCÊNCIA: RELATO DE QUATRO CASOS}

Alessi R, Canavezzi AZ, Cvintal V, Ito LM, Novais MAB, Kelendjian JF, Reato LFN, Xavier WC

alessi@uol.com.br

Introdução: países subdesenvolvidos como o Brasil apresentam elevada incidência de hanseníase; entretanto, existem poucos estudos sobre o aparecimento e evolução desta doença em indivíduos menores de quinze anos. Os relatos encontrados afirmam que a forma clínica predominante nesta faixa etária é a paucibacilar, e que a evolução para formas incapacitantes é rara. Relato de Caso: quatro casos foram acompanhados (janeiro/ 2000 - maio/2003) no ambulatório de hanseníase do CSE Capuava, realizando avaliação clínica, histológica e bacterioscópica das lesões dermatológicas, classificando-as em paucibacilares ou multibacilares e administrando poliquimioterapia. Através de exames clínicos buscaramse focos familiares e possíveis contactantes, submetendo-os também à aplicação de BCG intradérmica. Três casos eram de hanseníase dimorfa virchowiana, sendo que a reação reversa tipo I e o acometimento de nervo ulnar estiveram presentes em apenas um deles. O quarto caso apresentou hanseníase virchowiana. Comentários: os casos descritos contrariam a literatura apresentando formas polarizadas (dimorfo-virchowiana e virchowiana) com seqüelas incapacitantes e inestéticas, denunciando diagnóstico tardio. Devido ao longo período de incubação, os pacientes provavelmente contraíram a doença na infância. Em todos constatou-se a presença de fatores ambientais e em apenas um caso foi confirmado foco familiar de contágio. Sendo uma doença incomum na faixa etária infanto-juvenil, o diagnóstico inicial nesta fase não é feito na maioria dos casos, levando a repercussões agressivas. Por isso é fundamental a divulgação dos sintomas dessa afecção para o controle de endemias através da deteç̧ão e tratamento precoces a fim de reduzir a ocorrência de incapacidades funcionais e estéticas permanentes.

Descritores: Hanseníase. Adolescência. Infância.

\section{HEMIAGENESIA DA GLÂNDULA TIREÓIDE ASSOCIADA À} TIREOIDITE DE HASHIMOTO

Alvarez CR, Barella SM, Fernandes APC, Moysés NA, Moysés RA, Pinto FN, Sanjar FA, Zaccarelli MA

nadiaam@uninet.com.br

Introdução: A agenesia do lobo ou do ístmo tireoidiano é uma anomalia congênita rara. A Tireoidite de Hashimoto é uma doença auto-imune crônica que leva invariavelmente a um quadro de hipotireoidismo primário. A associação de hemiagenesia a outras doenças tireoidianas tem sido relatada Relato de Caso: É descrito caso raro de uma paciente de 29 anos com hemiagenesia de lobo direito e agenesia de istmo tireoidiano em associação com Tireoidite de Hashimoto. Após confirmação clínica, hormonal, imunológica e por exames de imagem, foram iniciadas doses crescentes de Levotiroxina sódica, alcançando-se o eutireoidismo clínico e laboratorial com $75 \mathrm{mg}$ por dia. Comentários: O caso relatado mostra a importância da anamnese e exame físico associados aos exames hormonais, imunológicos e de imagens em diagnosticar a rara associação de hemiagenesia com Tireoidite de Hashimoto. A paciente portadora de hemiagenesia de tireóide permaneceu em eutireoidismo durante anos e a causa do hipotireoidismo primário foi a Tireoidite de Hashimoto.

Descritores: Hemiagenesia. Glândula tireóide. Tireoidite de Hashimoto. Hipotireoidismo. Relato de caso.

\section{HÉRNIA DE SPIEGHEL}

Akita Júnior J, Dall' Olio G, Cagno Filho R, Guimarães SO, Henriques AC, Luz LT, Speranzini MB

dr.giancarlo@uol.com.br

Introdução: Os autores apresentam a partir de um relato de um caso de uma paciente atendida no Hospital Estadual Mário Covas - Santo AndréSP, a incidência, definição, apresentação, métodos diagnósticos e tratamento da hérnia de Spieghel com base em revisão de literatura. Relato de Caso: Paciente de 75 anos com queixa de abaulamento em fossa ilíaca esquerda há cinco anos com antecedente cirúrgico de uma cesareana e três herniorrafias incisionais. Ao exame físico IMC de 30,1, abaulamento em fossa ilíaca esquerda e hipogástrio margeando a extremidade lateral da incisão operatória de cesareana prévia região onde se palpava um tumor redutível com manobras manuais, visível a manobra de Valsava e sem identificação do anel herniário. Comentários: O diagnóstico é essencialmente clínico e os sintomas, quando presentes, manifestam-se como massa palpável, dor ou a combinação de ambos, seu tratamento é cirúrgico e os resultados são favoráveis com nenhum ou escasso número de recidivas. Hérnia ventral rara manifesta-se com ausência de sinais clínicos consistentes levando, muitas vezes, o seu diagnóstico para o intra-operatório devendo o cirurgião estar preparado para enfrentar esse possível desafio.

Descritores: Spieghel. Hérnia. 
060. ISQUEMIA MIOCÁRDICA INDUZIDA PELA INFUSÃO DE 5FLUOROURACIL

Bordinhon TS, Ferlin F, Ferreira C, Gomes ALR, Meneghini A, Santos RK adrianagomes_32@hotmail.com

Introdução: O 5-FU é um antimetabólito usado no tratamento quimioterápico em diversas neoplasias. Diversos autores reportam uma possível cardiotoxicidade relacionada com a droga, cuja incidência varia entre 1,2 a 18\%. Relato de Caso: Paciente masculino, 50 anos, portador de AIDS, carcinoma espino celular de canal anal e uso crônico de drogas antiretrovirais, sem antecedentes cardiológicos. Após infusão de 5-Fluorouracil (5-FU), apresentou dor precordial típica e prolongada, que cedeu com Nitroglicerina (NTG) endovenosa. Foi submetido a estudo eletrocardiográfico (ECG), ecocardiograma, dosagem de enzimas cardíacas e cinecoronariografia. As dosagens de enzimas cardíacas e o ecocardiograma foram normais. O ECG de repouso mostrou isquemia subendocárdica em parede ântero-septal do ventrículo esquerdo que se normalizou após o uso de NTG. Realizada Cinecoronariografia que mostrou artérias coronárias e ventrículo esquerdo normais. Comentários: O mecanismo da cardiotoxicidade do 5-FU ainda não foi completamente elucidado, podendo ser: 1 . reação auto-imune; 2. reação inflamatória; 3. efeito tóxico direto sobre as células miocárdicas; 4. pericardite; 5 . espasmo coronariano ${ }^{2,3} 3$ e 4 . Atualmente, a teoria mais aceita é a de espasmo coronário. O levantamento da literatura revela que a complicação é bastante rara, aventando-se a participação do endotélio alterado pelo uso crônico de anti-retrovirais, e de espasmo coronário desencadeado pelo citostático. As alterações metabólicas causadas pelo uso de inibidores de proteases têm como efeito colateral principal a ocorrência de doença arterial coronária prematura, o que, provavelmente, foi o fator desencadeante neste caso. Embora rara, a complicação deve ser lembrada e a infusão de 5-fluorouracil interrompida, especialmente nos pacientes submetidos previamente a tratamento com drogas anti-retrovirais.

Descritores: Angina de Prizmetal. Anormalidades induzidas por drogas.

\section{LABIRINTOPATIA MULTIFATORIAL: RELATO DE CASO}

Anadão CA, Bellelis P, Rappoport PB, Ribeiro LM, Samano EST

patrickbellelis@uol.com.br

Introdução: Vertigem e outros tipos de tontura estão entre os sintomas mais comumente encontrados no mundo. Estima-se que pelo menos $10 \%$ da população mundial apresente sensações de alteração do equilíbrio corporal, e que em aproximadamente $85 \%$ dos casos, esses sintomas são decorrentes de disfunção do sistema vestibular. A doença de Meniére parece ser a labirintopatia mais freqüente em adultos e idosos, sendo rara a sua observação em crianças e adolescentes. Todavia, outras causas de labirintopatias foram descritas como as de origem metabólicas, vasculares e ortopédicas, psíquicas e medicamentosas. Relato de Caso: O paciente em estudo era do sexo masculino, branco, com 72 anos de idade. Sua queixa principal era piora da tontura nos últimos trinta dias. Paciente referia um quadro de tontura rotatória por mais de 20 anos com piora nos últimos trinta dias, com duração de alguns segundos e desencadeada por alterações do posicionamento da cabeça. Relata que a tontura surgia várias vezes ao dia com episódios de náusea concomitante. Relata zumbido freqüente e pior à noite, além de hipoacusia progressiva, não flutuante durante todo este período. De doenças associadas apresentava dislipidemia, DM, hipotireoidismo, osteoartrose cervical, fibrilação atrial, e fazia uso de beta-bloqueador.Desta forma podemos inferir que se trata de uma labirintopatia multicausal. Comentários: São discutidas as diversas causas metabólicas, vasculares e ortopédicas para a labirintopatia apresentada pelo paciente em questão.

Descritores: Labirintopatia. Meniere. Tontura. Zumbido. Hipoacusia.

062. N-METIL-GLUCAMINA (GLUCANTIMER) E INSUFICIÊNCIA RENAL AGUDA NO TRATAMENTO DA LEISHMANIOSE MUCOCUTÂNEA: RELATO DE UM CASO.

Diament M, Elias KM, Furlan CC, Furtado JJD, Nery SB

magridiament@terra.com.br
Introdução: A Leishmaniose muco-cutânea é uma zoonose autóctone do Novo Mundo, causada pelo protozoário do gênero Leishmania, e é transmitida pela picada dos insetos flebotomíneos. O antimoniato de $\mathrm{N}$ metil-glucamina (Glucantime ${ }^{R}$ ) é a droga de escolha no tratamento das Leishmanioses cutâneo mucosa e visceral, sendo mais eficaz e menos tóxica que seus precursores trivalentes. Relato de Caso: Paciente de 58 anos, submetido a tratamento com N-metil-glucamina, que evoluiu com elevação dos níveis séricos de uréia e creatinina (insuficiência renal não oligúrica). Estes efeitos colaterais levaram à suspensão da medicação no quinto dia de tratamento. O paciente foi a óbito no décimo primeiro dia de internação. É importante ressaltar que, ao início da terapêutica, a função renal do paciente era normal. Comentários: O paciente relatado apresentou IRA devido ao tratamento com $\mathrm{N}$-metil-glucamina, que acreditamos ter desempenhado papel fundamental na má evolução do seu quadro.

Descritores: N-metil-glucamina. Antimoniais prevalentes. Efeitos colaterais. Nefrotoxidade.

\section{POLIPOSE LINFOMATOSA MÚLTIPLA DO INTESTINO GROSSO: RELATO DE DOIS CASOS E REVISÃO DA LITERATURA}

Catelani LGC, Gonçalves S, Lopes LS, Neto JZA, Polycarpo A, Topciu FR, Waisberg J, Zerwes MHT

leo.sl@ig.com.br

Introdução: A polipose linfomatosa múltipla gastrintestinal (PLMG) é um tipo raro de linfoma maligno de comportamento biológico agressivo, com disseminação sistêmica precoce e prognóstico sombrio. Ocorre mais freqüentemente no sexo masculino em relação ao feminino e a média de idade de maior incidência é de 50,6 anos. A doença apresenta padrão nodular característico de infiltração submucosa que origina pólipos cólicos múltiplos, geralmente sésseis, por acúmulo de tecido linfóide maligno. Os diagnósticos diferenciais principais são: pólipos adenomatosos, polipose hereditária familiar, síndrome de Peutz-Jeghers e hiperplasia nodular linfóide com hipogamaglobulinemia. Relato de Caso: Homem, 59 anos, queixas de astenia e cansaço aos pequenos esforços há seis meses, sudorese noturna há três meses e alteração do hábito intestinal e emagrecimento de 14 quilos há dois meses. No exame físico havia massa palpável em epigástrio, mesogástrio e quadrante superior esquerdo do abdome.; A endoscopia digestiva alta mostrou presença de pólipos gastroduodenais múltiplos variando de 0,1 a $0,5 \mathrm{~mm}$ no seu maior eixo; o exame anátomo-patológico dessas lesões polipóides revelou intenso infiltrado linfocítico atípico no cório. A tomografia computadorizada (TC) do abdome mostrou A biópsia retal revelou infiltrado linfocítico atípico sugestivo de infiltração por linfoma linfocítico. Mulher, 76 anos, branca, relatava, há três meses, astenia, diminuição do apetite e cerca de quatro a cinco evacuações de fezes líquidas por dia, sem a presença de sangue ou muco. Referia emagrecimento de seis quilos em seis meses. As tomografias computadorizadas do abdome e do tórax não revelaram comprometimento extra-intestinal. A colonoscopia revelou presença de lesões polipóides no reto, sigmóide, colo descendente e flexuras esquerda e direita. O exame histopatológico de biópsia das lesões retais revelou infiltração da parede do órgão por linfoma de pequenas células, de baixo grau. Comentários: O tratamento cirúrgico não é recomendado devido à localização múltipla no trato gastrintestinal e freqüente envolvimento extradigestivo da lesão. O tratamento de escolha é a quimioterapia, sendo a cirurgia reservada apenas para obstrução intestinal, peritonite por perfuração intestinal e hemorragia digestiva baixa intensa. No presente trabalho são apresentados dois casos de PLMG e discutidos os aspectos anátomos-patológicos, clínicos, do diagnóstico e do tratamento desta inusitada neoplasia.

Descritores: Polipose linfomatosa múltipla. Linfoma não-Hodgkin. Linfoma das células do manto. Neoplasias colo-retais. Imunohistoquímica.

\section{PONTE MIOCÁRDICA E ARTÉRIA CORONÁRIA ÚNICA: RELATO DE UM CASO E REVISÃO DE LITERATURA}

Barbosa FBS, Bordinhon TS, Ducatti LSS, Ferreira C, Gomes ALR, Novais LAB, Silveira JA, Valente T

thais32@uol.com.br 
Introdução: Ponte miocárdica é uma entidade anatômica onde uma artéria epicárdica percorre um trajeto intramiocárdico de extensão variável. Artéria coronária única é uma anomalia congênita rara na qual uma única artéria surge do tronco aórtico por um óstio coronário único suprindo todo o coração. Relato de Caso: Os autores relatam um caso de paciente feminina, de 43 anos, com quadro clínico de dispnéia aos esforços acompanhada de precordialgia com melhora ao repouso. Apresentava múltiplos fatores de risco para doença coronariana. Foi submetida a vários exames. No teste ergométrico mostrou uma isquemia nas derivações precordiais anteriores, a cinecoronariografia evidenciou uma artéria coronária única emergindo do seio de Valsalva direito que dela originava a artéria coronária direita, circunflexa e descendente anterior que em seu terço proximal apresentava ponte miocárdica. Comentários: Os primeiros relatos de ponte miocárdica em cadáveres ocorreu em 1951 e em cinecoronariografias ocorreu na década de 60 . Indivíduos com ponte miocárdica podem apresentar, durante a sístole, uma redução no fluxo coronariano que pode ser responsável por isquemia miocárdica, infarto miocárdico, arritmias ventriculares e morte súbita cardíaca. Por outro lado o seguimento da artéria coronária distal à ponte miocárdica apresenta um menor risco de desenvolver lesão aterosclerótica.

Assim como a ponte miocárdica as anomalias coronarianas congênitas podem estar associadas com infarto agudo do miocárdio, síncope, fibrilação ventricular não fatal, morte relacionada ao exercício e morte súbita. Tanto a ponte miocárdica quando a artéria coronária única são entidades benignas e raras, a associação delas parece nunca ter sido antes descrita.

Descritores: Anomalias dos vasos coronários. Coronariopatia. Vasos coronários.

\section{RECIDIVA LOCAL DE ADENOCARCINOMA GÁSTRICO APÓS GASTRECTOMIA:}

Arita JH, Bagarollo C, Godinho CA, Henriques AC, Kunisawa CM, Pires SP, Topciu FR, Waisberg J

flavia_topciu@bol.com.br

Introdução: O adenocarcinoma gástrico é o tumor maligno mais comum do estômago e o tratamento consiste na sua ressecção cirúrgica. A ocorrência de recidiva é freqüente e, nestes casos, a abordagem cirúrgica apresenta, na maioria das vezes, resultados insatisfatórios. Relato de Caso: Paciente do sexo masculino, 40 anos, apresentou recidiva local de adenocarcinoma gástrico avançado. Optou-se pela reoperação, conseguindo surpreendentemente bons resultados. Comentários: A recidiva local de adenocarcinoma gástrico indica que a ressecção cirúrgica não foi bem sucedida. A incidência da recidiva local na literatura é bem variável, encontrando-se valor mínimo de $10 \%$ e máximo de $36 \%$. Esta incidência da recidiva é influenciada pela localização do tumor, presença de margem de ressecção comprometida e extensão da margem de segurança. O diagnóstico da recidiva é feito pela história clínica e outros exames complementares. O tempo médio livre de doença é de 15 meses e está diretamente relacionado com a ressecabilidade. O prognóstico do adenocarcinoma gástrico recidivado depende do estadiamento do tumor, do tratamento cirúrgico e do tempo livre de doença. A recidiva local é comum e depende de vários fatores predisponentes, a maioria dos quais pode ser prevenida. Apesar da taxa de ressecabilidade ser baixa, a reoperação aumenta a sobrevida média dos pacientes sem acometimento linfonodal e sem metástases.

Descritores: Recidiva local. Adenocarcinoma gástrico. Estômago.

066. Síndrome de Boerhaave: relato de caso e revisão de literatura

Cardelino BO, Cardoso APG, Den Julio A, Grandhini M, Novaes JY, Orel M, Romano TG, Silva EC

tgromano@ig.com.br

Introdução: A ruptura espontânea de esôfago, também chamada de Síndrome de Boerhaave, ocorre subitamente e gera risco de vida. Em 80\% dos casos é precedida por episódios de vômitos intensos. A Síndrome de Boerhaave não é diagnosticada inicialmente em $50 \%$ dos casos. Isto porque sua apresentação clínica mimetiza uma série de situações freqüentemente deparadas pelos profissionais médicos, tais como aneurisma dissecante de aorta, infarto miocárdico, doença péptico dolorosa, pancreatite aguda, pericardite e pneumotórax. A necessidade de uma abordagem terapêutica precoce, a baixa incidência, a semelhança clínica com outras patologias e o risco de contaminação cervical, mediastínica e torácica são fatores que quando somados resultam numa taxa de mortalidade de $25-30 \%$ quando o tratamento ocorre antes de 24 horas a partir da ruptura e de $45-55 \%$ quando decorrem mais de 24 horas.

Relato de Caso: M.M.F., sexo masculino, 42 anos, procurou o serviço de pronto atendimento do CHSA com queixa de desconforto torácico há 6 horas e história de dois episódios de vômitos intensos há 12 horas após ingestão alcoólica. Ao Raio-X de tórax, verificou-se a presença de um hidropneumotórax a esquerda de grau moderado. Realizada drenagem de hemitórax esquerdo com saída de material purulento (aproximadamente $200 \mathrm{ml}$ ) e ar, em seguida, foi feita a internação do paciente na enfermaria da clínica cirúrgica do hospital em questão. Foi submetido, após cinco dias da drenagem torácica a uma decorticação pulmonar esquerda, devido a manutenção de débitos moderados. Durante o ato operatório foi encontrada uma grande quantidade de restos alimentares habitando a cavidade pleural difusamente apesar de não ter sido encontrada evidência de fístulas digestivas. Permanecendo sob drenagem pleural esquerda e, novamente, mantendo débitos de aspecto purulento em moderada quantidade, realizouse uma esofagoscopia flexível que evidenciou perfuração esofágica de aproximadamente $10 \mathrm{~mm}$ de diâmetro na parede lateral esquerda, cerca de $1 \mathrm{~cm}$ acima da transição esôfagogástrica, indicando-se correção cirúrgica ainda que não houvesse sinais ou sintomas de septicemia. Submetido, no décimo segundo dia após à perfuração esofágica a esofagorrafia tóracoabdominal, confecção de válvula antirrefluxo com fundo gástrico (técnica de Lindt) e procedimento de Belsey-Mark V, além de patch esofágico com retalho pleural mais drenagem dupla de hemitórax esquerdo sob selo d'água - por perfuração linear desde 3 últimos centímetros de esôfago torácico até primeiro centímetro do abdominal, evoluindo sem complicações intraoperatórias ou pós-operatórias, permanecendo com dieta por sonda enteral até o décimo terceiro do pós-operatório, quando recebeu alta hospitalar. Comentários: A ruptura espontânea do esôfago (Síndrome de Boerhaave) é particularmente difícil de ser diagnosticada, primeiro pela sua baixa incidência e segundo pela grande quantidade de diagnósticos diferenciais possíveis, descritos na literatura como motivo de abordagem terapêutica equivocada. Porém, deve ser lembrada uma vez que o tratamento precoce é responsável pelo melhor prognóstico.

Descritores: Boerhaave. Perfuração de esôfago. Terapêutica.

\section{XANTOMA COMO MANIFESTAÇÃO CUTÂNEA DE DISLIPIDOSES: RELATO DE QUATRO CASOS}

\section{Alessi R, Canavezzi AZ, Cvintal V, Ito LM, Kelendjian JF, Xavier WC}

alessi@uol.com.br

Introdução: a habilidade de reconhecer diversas formas clínicas de xantomas como a forma tuberosa, eruptiva, tendinosa e xantelasma demonstra-se de extrema importância no diagnóstico de diferentes doenças sistêmicas de base. Tal capacidade auxilia o médico na prevenção, e conseqüente tratamento, de doenças potencialmente letais, como a hiperlipoproteinemia, como discutido neste trabalho. Relato de Caso: o ambulatório da disciplina de dermatologia da Faculdade de Medicina do ABC acompanhou quatro casos de pacientes em que, a partir de lesões cutâneas, observou-se a presença de doenças de bases; os casos foram acompanhados durante o período de novembro de 2002 a abril de 2003. Os diagnósticos encontrados foram: (a) xantoma eruptivo levando ao diagnóstico de hiperlipidemia tipo $\mathrm{V}$ e diabete mellitus; (b) xantelasma levando a ulterior diagnóstico de hiperlipidemia tipo II e diabete mellitus II; (c) xantoma tuberoso diagnosticando posteriormente hiperlipidemia tipo I; (d) xantoma tendinoso diagnosticando ulteriormente hiperlipidemia tipo II. Comentários: a partir do acompanhamento dos casos e comparação com a literatura observou-se uma concordância, sendo encontrada relação entre a morfologia da lesão cutânea e a doença de base. O conhecimento destas lesões cutâneas por todos os médicos é de extrema importância uma vez que permite o diagnóstico de doenças potencialmente letais.

Descritores: Xantoma. Hiperlipidemia. Dislipidoses. Diabetes Mellitus. 